\title{
Jesús y la justicia. Reflexiones para occidente
}

\author{
Jon Sobrino, \\ Centro de Reflexión Teológica, \\ San Salvador.
}

En esta exposición' no voy a ofrecer un análisis b́blico de la relación entre Jesús y la justicia ${ }^{2}$. Quisiera ofrecer, más bien, algunas reflexiones sobre algo que está ocurriendo en nuestro mundo, específicamente en occidente, también, en muy buena parte, en la Iglesia e incluso en la teología. Me refiero al silencio que se ha cemido sobre la injusticia y la justicia, la necesidad de superarlo y en qué puede ayudar Jesús de Nazaret.

En efecto, a diferencia de lo que ocurría hasta hace algunos años, no se usan ya términos como injusticia y justicia para describir lo que es nuestro mundo y lo que debiera ser. Los términos casi han desaparecido, o, dicho con mayor precisión, han sido enterrados. Y con ello, se ha ido diluyendo también una constelación de términos que solían ser considerados fundamentales: opresión y liberación, víctimas y martirio, pecado estructural y santidad política, praxis y esperanza de que el verdugo no triunfe sobre la víctima. En una palabra, se ha debilitado mucho todo lo que es profecía y utopia, y la tarea de "revertir la historia".

1. Este texto es una reelaboración de la ponencia tenida el 10 de febrero de 2004, en la Cátedra de Teología Contemporánea del CMU Chaminade durante el curso 20032004. Terminé de reescribirlo el 6 de junio de 2004, y por eso se mencionan algunos hechos más recientes.

2. R. Aguirre, "Jesús de Nazaret. El amor que lleva a la justicia", en Rafces brblicas de la fe, Madrid,1997, pp. 33-62; J. I. González Faus, "Dogmática cristológica y lucha por la justicia", Revista Latinoamericana de Teología, 34 (1995), 37-57; E. Nardoni, Los que buscan la justicia. Un estudio de la justicia en el mundo biblico, Estella, 1997, pp. 183-205; R. Sivatte ef al., La justicia que brota de la fe, Santander, 1985; A. Rosillo, Que fluya la justicia. Justicia y derechos humanos en los texios brblicos. Una lectura jurfdica, México, 2003. 
En este contexto, queremos recordar algunos elementos importantes de las tradiciones evangélicas para ver en qué ayuda Jesús. Pero antes de hacerlo es bueno comprender por qué se ha ido diluyendo el binomio injusticia-justicia y que es necesario para devolverlas a la conciencia.

\section{Problema previo: la honradez ante lo que ocurre en nuestro mundo}

\subsection{El lenguaje a favor o en contra de lo real}

Es sabido que quien controla el lenguaje, y más las definiciones, ha ganado gran parte de las batallas, en las que estamos inmersos los humanos.

Los poderosos se apoderan de las palabras, inventan unas y entierran otras. Un ejemplo importante es lo ocurrido durante la catástrofe de Rwanda, ahora hace diez años, en abril de 1994, que ha vuelto a salir a la luz. La entonces secretaria de Estado de Estados Unidos, Madalaine Albrigh, prohibió el uso del término genocidio para describir las matanzas, pues ello habría obligado a Naciones Unidas a intervenir. Y Boutros Boutros-Ghali, por su parte, Secretario General de Naciones Unidas, a finales de abril, todavía continuaba hablando de guerra civil, no de genocidio. Ahora, el general Dallaire, canadiense, enviado por dicha organización a Rwanda, en 1994, como comandante de una misión de paz, acaba de decir la verdad que se escondía tras ese manejo del lenguaje. "Nadie estaba interesado en venir a Rwanda y arriesgarse a sufrir bajas"'. Si no había genocidio, no habra obligación de intervenir. Y occidente no hizo nada para evitar la debacle de Rwanda.

Otro ejemplo en la dirección contraria, que proviene no de poderosos, sino de profetas. Estados Unidos está imponiendo su voluntad al mundo: guerras en Afganistán, Irak, Palestina, economía injusta, comercio inicuo, engaño y mentira, desprecio a los derechos humanos, en Guantánamo, y sin ningún pudor, en Abu Ghraib. Impone el calendario, el 11-S, y, más de fondo, impone una cultura y una visión del ser humano: la exaltación del individuo, el éxito y el disfrute del buen vivir. Pues bien, en esta situación ha resucitado un lenguaje que parecía enterrado, el imperio, pues otros lenguajes son ya insuficientes para describir la realidad. José Comblin también lo ha hecho, y, por cierto, con este recordatorio. "San Agustín llamaba al imperio romano una inmensa obra de bandidos, magnum latrocinium. Y lo mismo puede decirse de los imperios contemporáneos. Son pecados $y$ fuentes de pecados"4.

3. CoLatino, San Salvador, 13 de abril de 2004, p. 24.

4. J. Comblin, "Guatemala: nunca más, o el desafío para la vida humana", en Monseñor Julio Cabrera, editor, Memoria y testigos de Guatemala, Guatemala, 200I, p. 191. 
El primer ejemplo muestra cómo la palabra encubre la realidad, y el segundo, muestra cómo la palabra deja ser real a la realidad. En cualquier caso, unos y otros están muy interesados en qué palabra usar para decir qué es lo real. Y en este contexto universal del uso o no uso de un lenguaje, nos preguntamos qué ocurre hoy con el lenguaje de justicia-injusticia, y por qué.

Ese lenguaje era normal hace años, ciertamente desde Medellín y en la teología de la liberación, pero se ha ido diluyendo. Para expresar lo negativo, ahora se usan términos como subdesarrollo, países en vias de desarrollo, clases menos favorecidas, y también se habla de guerra y terrorismo, obviamente, pero casi no se habla de injusticia. Para expresar lo positivo, se usan términos como democracia, diálogo, cooperación y solidaridad intemacional, prosperidad, progreso, derechos humanos, Estado de derecho - cosas buenas, aunque se afirmen con mayor o menor verdad o hipocresia-, pero casi no se habla de justicia.

El silencio es clamoroso y la razón puede ser la siguiente. El lenguaje de injusticia desenmascara la verdad y la tragedia de este mundo como ningún otro, y el lenguaje de justicia expresa la radicalidad, urgencia y ultimidad de lo que debemos hacer los seres humanos, y sin excusas. En si mismo, ese lenguaje expresa realidades dialécticas, que hoy se rehuyen, y el lenguaje se sustituye por otro que exprese diálogo, tolerancia, complementariedad. Pero por mucho que adomemos el concepto y el lenguaje, la realidad de nuestro mundo, vista, vivida y sufrida desde el abajo de la historia, es una realidad deplorable y tiene como causa mayor la injusticia. En palabras lapidarias dice José Comblin: "en realidad la humanidad está dividida entre opresores y oprimidos".

Hablar de justicia e injusticia apunta, pues, a dos cosas. Significa hablar de opresión entre los seres humanos, de situación de guerra, término usado por Juan Pablo II para describir la injusticia económica planetaria, aun en tiempos de paz ${ }^{5}$. Y significa la urgencia e incondicionalidad de revertir la historia actual. Ninguna de estas cosas es fácil de aceptar en occidente.

Y para el creyente, no hablar así, significa ignorar lo central de la voluntad de Dios: la justicia del reino mesiánico, que anunció Jesús. Y significa cerrarse al acceso a Dios, según aquello de Jeremías: "hacer justicia ¿no es eso conocerme?, dice Yahveh" (Jer 22, 15s; cfr. Os 6,6).

Recuperar el lenguaje de injusticia-justicia, sin embargo, no es fácil. Para ello se necesita la honradez con lo real, la voluntad de ser real y la voluntad de nombrar lo real. Veámoslo.

5. Pastores Gregis, 16 de octubre, 2003, n. 67. "Hoy más que ayer, la guerra de los poderosos contra los débiles ha abierto profundas divisiones entre ricos y pobres. ¡Los pobres son legión! En el seno de un sistema económico injusto, con disonancias estructurales muy fuertes, la situación de los marginados se agrava de día en día. En la actualidad hay hambre en muchas partes de la tierra, mientras en otras hay opulencia". 


\subsection{La honradez con lo real}

En nuestro mundo hay un déficit clamoroso de respeto elemental hacia la realidad: dejar que la realidad sea lo que es, sin ignorarla, encubrirla o maquillarla. Hay infinidad de conocimientos que superan el desconocimiento de cosas concretas, pero no hay mucha verdad que supere la mentira, la cual no es simple desconocimiento, sino encubrimiento.

Eso ocurte de varias formas. A través del silencio, mientras éste sea posible; a través de la mentira y la manipulación, cuando se hacen necesarias y se pretende mantener un mínimo de vergüenza, y a través de la tergiversación y aun la santificación del mal, cuando se cae en la desvergüenza total, haciendo pasar por bueno lo que es malo. Todo esto ocurre hoy en occidente. Se repite lo que denunciaba Isaras hace 2600 años: “ $i A y$ de los que llaman al mal bien y al bien mal; que dan oscuridad por luz y luz por oscuridad; que dan amargo por dulce y dulce por amargo" (Is 5, 20). Y lo que denunciaba Pablo hace 2000 años: "aprisionan la verdad con la injusticia" ( $c f r$. Rom $1,18 s s$ ). Los ejemplos son infinitos, y Eduardo Galeano y Noam Chomsky nos mantienen al día. Baste recordar cómo la coalición habla de lo que ocurre en Irak y lo que se hace con Irak.

Pues bien, si el ser humano tiene que "dejar a Dios ser Dios", igualmente tiene que "dejar a la realidad ser real". No significa esto, obviamente, dejarla como está, pero sí ponerla en palabra como es. En definitiva, significa admitir, ante todo, su existencia. ¿Existe Irak? ¿Es una realidad en sí y para sí, o sólo es real, en cuanto tenga relación, buena o mala, con occidente? ¿Es un accidente de occidente, el cual decidirá lo que en Irak puede haber o no de sustancia? Un ejemplo más claro: ¿existe Africa, existe el coltán, existen los cuatro millones de muertos en la guerra del Congo, en los últimos seis años?

El primer paso de la honradez con lo real es aceptar la existencia de lo real. De lo contrario, no hay que extrañarse de que no se hable de injusticia-justicia. No son reales. No existen. "La verdad les hará libres", dice Jesús, lo cual suele ser citado con bastante aprobación como cosa biensonante. Pero, al menos con anterioridad lógica, hay que recalcar que, antes que nada, la verdad expresa y otorga existencia a las cosas. Y, además, sin reconocer esa existencia, la libertad es inane.

\subsection{La voluntad de ser reales}

Dicen los expertos que el mayor peligro para el cristianismo fue desde el principio el docetismo (junto con el gnosticismo). El docetismo, venía a decir que el Cristo no tenía came. Con mayor precisión, la sarx de Cristo, la carne en cuanto débil, no era cosa real, sino sólo aparente. Pues bien, como toda herejía significativa, el docetismo pervive en nuestro mundo. 
Docetismo es vivir en la irrealidad, por ejemplo, en las islas de abundancia y lujo de occidente dentro de un planeta mayoritariamente pobre y oprimido, como si aquello fuese lo real y esto fuera lo irreal, siendo las cosas al revés. Y es justificado, aun sin decirlo, porque ése es el destino manifiesto de occidente. Occidente lo ha invocado, nomnalmente en silencio, pero a veces aparatosamente, para depredar y oprimir al resto del mundo. Y lo sigue haciendo. Dicho de manera un poco sofisticada, ese destino manifiesto consiste, ante todo, en existir $y$ no en un existir cualquiera, sino en el buen vivir. El mal vivir es, en la práctica, el destino manifiesto del tercer mundo. Así, la postración de África pudiera plantear - ojalá - un problema ético, pero no metafísico: a la realidad africana le serfa inherente el mal vivir. $\mathrm{Y}$ al contrario: el buen vivir le es inherente a occidente.

Esto viene de lejos, y con frecuencia ha sido sacralizado. Muchas veces se ha invocado la idea de elección y predestinación divinas para justificar el destino manifiesto. Pero también se mantiene en forma secularizada: "nosotros somos lo humano", han dicho europeos y norteamericanos; no los indígenas de América Latina, África y Asia. "Nosotros", dice occidente, "somos la medida de todas las cosas", lo que los griegos sólo decían del ser humano. Occidente mide la realidad, pero no deja ser medido por la realidad más global del planeta. Es la expresión del docetismo prepotente: no querer vivir en la realidad doliente de este mundo.

Al docetismo se le opone lo real, y, antropológicamente, la voluntad de ser real. De ello da ejemplo el mismo Dios: ho logos sarx egeneto (Jn 1, 14). Para hablar de justicia-injusticia hay que empezar por superar el docetismo y decidirse a vivir en lo real. De otra forma, aquéllas seguirán enterradas.

\subsection{Nombrar lo real}

En occidente es frecuente - y es bueno- que existan debates. En la televisión son muy frecuentes. En Estados Unidos sobre todo se usa con mucha frecuencia la expresión de que algo es controversial, con el matiz que tiene en el inglés estadounidense: hay diferentes opiniones y, en principio, todas son igualmente válidas; además, se suelen planificar esfuerzos para presentar así las cosas, de modo que lo que, por hipotesis es evidente, deje de serlo. Cierto es que hay muchos asuntos que, de derecho, deben ser objeto de debate y controversia, como los programas de diversos candidatos, en una campaña electoral. Pero hay otros que lo son sólo de hecho (y para algunos no debieran serlo de derecho), como la guerra preventiva contra Irak. Sin duda, lo importante es saber cuándo algo es controversial, debatible, de derecho o sólo de hecho, pero lo que me interesa hacer notar es lo siguiente: es indudable que la realidad se presta muchas veces a la controversia, pero se ha generado un modo de pensar según el cual lo importante es abordar la realidad desde lo que tiene de controversial. ¿Y 
entonces qué ocurre? Que ya no hay nada evidente, contundente, que no puede ser controversial, que no admite discusión. Por decirlo en concreto, todo, por horrible que sea, puede ser relativizado, al elevarlo a objeto de debate, al hacerlo controversial.

Indudablemente, siempre habrá diferencia de opiniones, pero que el silencio sobre África es macabro no debiera ser asunto de debate. Con esto quiero decir que lo controversial puede relegar a segundo plano la convicción de que hay algo real más allá de los debates. Que en la guerra de Irak se ha acumulado una serie de mentiras, injusticias, atroces violaciones de derechos humanos, asesinatos de civiles, de todo lo cual hay personas e instituciones responsables, está más allá de la controversia.

Con esto queremos decir que la realidad se densifica a veces de tal manera que no puede esconderse tras la controversia, ni ésta puede hacer desaparecer lo que de evidente tiene la realidad. Mencionemos sólo dos ejemplos - relacionados con el tema de justicia e injusticia - de cómo se hablaba de estas cosas, en tiempos pasados:

Existen muchos estudios sobre la situación del hombre latinoamericano. En todos ellos se describe la miseria que margina a grandes grupos humanos. Esa miseria, como hecho colectivo, es una injusticia que clama al cielo'.

Entre tantos signos como siempre se dan, unos llamativos y otros apenas perceptibles, hay en cada tiempo uno que es el principal, a cuya luz deben discernirse e interpretarse todos los demás. Ese signo es siempre el pueblo históricamente crucificado, que junta a su pemnanencia la siempre distinta forma histórica de su crucifixión?.

Esa lógica en el modo de pensar la realidad se basa en un presupuesto: la realidad se puede densificar de tal manera que se puede convertir en algo no debatible. Es la lógica que está detrás de lo que el Vaticano II llamó "los signos de los tiempos" (GS 4). Hay que discernirlos, debatirlos, si se quiere, pero una vez discemidos y sacados a luz, no son ya debatibles. Se toman evidentes.

Se puede insistir, sin duda, en que todo es debatible, todo es controversial, como gustan de decir en Estados Unidos, sobre todo los medios. Sólo dejaŕa de ser objeto de debate el que no existe lo meta-debatible. Pero sea de esto lo que fuere, y reconociendo el gran aporte de la tradición anglosajona al debate, pienso que sí hay realidades que se imponen por sí mismas a una conciencia humana y cristiana. O digamos, por lo menos, que, si su realidad no se impone por sí misma, siempre permanecerán debatibles, y a la postre, perderán obviedad, im-

6. Medellin, Justicia, n. 1, 1968.

7. I. Ellacuría, "Discemir 'el signo' de los tiempos", Diakonia, 17 (1981), 58. 
portancia y hasta existencia. " $¿ I n j u s t i c i a$, fracaso, crueldad de occidente? Es debatible", dirán. Y todo seguirá sustancialmente igual.

No hemos mencionado todavía cuál puede ser el aporte de la tradición bŕblico-jesuánica a la justicia, pero lo dicho puede ayudar a ubicamos de forma correcta, en un mundo que es de injusticia y necesita justicia. Que esto no es controversial, ni debatible, me parece cartesianamente claro y distinto. De todas formas, baste mencionar dos recordatorios de estos días.

Irene Khan, directora de Amnistra Internacional, ha dicho en Londres que, después del 11 de septiembre de 2001, "los gobiemos están perdiendo su rumbo moral, sacrificando los valores mundiales de los derechos humanos en una búsqueda ciega de seguridad". . Un alto miembro de la FAO ha denunciado en Guatemala que "en las calamidades de la región, como parte del tercer mundo, incide sobremanera un pecado original, léase el desarrollo economico y social, deformado por siglos de dominio de las potencias coloniales, las mismas que con políticas proteccionistas distorsionan hoy el mercado mundial"s. "Perder el rumbo moral", por lo que toca al respeto de los derechos humanos, "permanecer en el pecado original", por lo que toca a no dar de comer a la humanidad, son palabras mayores. Y son aplicadas a occidente. Dice Leonardo Boff:

Cuando juzguen nuestro tiempo las generaciones futuras nos tacharán de bárbaros, inhumanos y despiadados por nuestra enorme insensibilidad frente a los padecimientos de nuestros propios hermanos y hermanas ${ }^{10}$.

\section{El aporte boblico-jesuánico a la justicia}

Veamos ahora el aporte de la tradición bíblico jesuánica a la justicia, en el contexto real que hemos descrito. Mencionaremos sólo algunos elementos de lo que hemos llamado la constelación de realidades alrededor de la justicia y la injusticia.

8. En su presentación del 26 de mayo, condenó los atentados de Al Qaeda, obviamente, pero también a occidente. Puestas juntas las violencias de ambos, "constituye el ataque más sostenido de los últimos 50 años contra los derechos humanos y el derecho internacional humanitario". En referencia a Estados Unidos dijo que "carece de visión y de principios".

9. Flavio Miragaia Perry, embajador de Brasil ante la sede de la FAO, en Roma. Y affade que "la ayuda del primer mundo para combatir el hambre y la pobreza (alrededor de 50 mil millones de dólares anuales) equivale a una séptima parte de los subsidios que dan a sus agricultores para producir artículos más baratos que compitan con ventajas en el mercado (350 mil millones de dolares)", tornado de CoLatino, San Salvador, 1 de junio, p. 5.

10. L. Boff, La oración de San Francisco, Santander, 1999, p. 98. 


\subsection{Jesús, profeta y maestro de la sospecha}

Justicia e injusticia toman formas diferentes, a lo largo de la historia. Son pues'análogas, y Jesús no ofrece un concepto estricto de ninguna de ellas. Pero sí muestra un talante en favor del oprimido para defenderlo activamente del opresor, en lo que consiste su gran aporte a la justicia. Lo resumimos en tres cosas: (a) el pasmo ante el agravio comparativo, (b) la ultimidad de la compasión y misericordia, (c) la indignación ante la opresión. Veámos cómo aparece esto, de forma paradigmática, en tres pasajes de los sinópticos" - fuesen palabras de Jesús o de la tradición a partir de Jesús.

\subsubsection{El pasmo ante el agravio comparativo}

El ricachón y el pobre Lázaro (Lc 16, 19-31). La parábola es conocida ${ }^{12}$. Su contenido puede provenir de una historia egipcia, conocida en una traducción al griego. El mensaje es doble. Por una parte, la inversión de valores en esta vida y en la otra por lo que toca a las posesiones materiales, lo que da un nuevo matiz a las bienaventuranzas y malaventuranzas, dirigidas a pobres y ricos $(L c 6,20.24)$. Por oura, la inmensa dificultad de que un rico se convierta - "ni aunque un muerto resucite", se dice-, pues la conversión no depende de milagros, sino de escuchar la ley y los profetas.

Detalle importante para comprender el talante de Jesús es que del ricachón no menciona el nombre, mientras que sí pone nombre al pobre: lo llama Lázaro. Quizás es lo único que tiene, pero eso le otorga dignidad, mientras que todo lo que el ricachón tiene es incapaz de otorgarle dignidad. Y es también importante el comentario de Fitzmyer más allá del texto: "No se puede negar que, al menos indirectamente, hay aquí una llamada a una dedicación sincera y generosa a todas las víctimas de la indigencia, de la enfermedad y de la multitud de desgracias que se cierne sobre el ser humano"'13.

Tampoco parece que se pueda negar, aunque no se explicite en el texto, el pasmo - y la indignación - que produce la mera yuxtaposición de los miserables de este mundo y de los ricachones. Para nuestro tema, esto quiere decir que, aunque por hipótesis la coexistencia de ricos y pobres no se debiese a la injusticia, el hecho de esa coexistencia, en sí misma, expresa una monumental debacle y un fundamental fracaso de la familia humana. Es el primordial agravio comparativo, logicamente previo incluso a dejarse afectar por la injusticia, y sin lo cual el dinamismo de la praxis de justicia mermará en vigor.

11. Nos remitimos más a Lucas, pues su evangelio, dada la situación de su comunidad, trata más en detalle el tema de pobres y ricos, justicia e injusticia.

12. Los breves comentarios están tomados de J. A. Fitzmyer, El Evangelio según Lucas III, Medrid,1987, pp. 746-755.

13. Ibrd., p. 754. 
Pues bien, el ricachón y el pobre Lázaro es la parábola de nuestro mundo actual, y el abismo entre ambos se agranda cada año. Como repite el PNUD, en el mundo había 1 rico por cada 30 pobres, en 1969; 1 por cada 60, en 1990; 1 por cada 74, en $1997^{14}$. Un bebé en Estados Unidos consume 420 veces más recursos que un bebé en Etiopía. En un campo de fútbol -ocurrió en Madrid hace tres años-, el costo de los 22 jugadores sobre el césped era más de dos veces el presupuesto del Tchad. No hace falta seguir.

Y el uso de los recursos con los que se podría revertir ese agravio es, asimismo, agraviante, además de cruel y mortifero. Acaba de decir Eduardo Galeano, por cierto en la ostentosa celebración - lo cual no deja de ser una ironía- de las diferentes culturas de la humanidad con la finalidad de propiciar la solidaridad entre los pueblos:

El mundo dedica 2,200 millones de dólares por día a la producción de muerte. O sea: el mundo consagra esa astronómica fortuna a promover cacerías donde el cazador y la presa son de la misma especie, y donde más éxito tiene quien más prójimos mata. Nueve días de gastos militares alcanzarían para dar comida, escuela y remedios a todos los niños que no tienen ${ }^{15}$.

Galeano no sólo apunta al agravio comparativo, sino a la crueldad - gastos para la muerte versus gastos para comida, escuela y remedios para niños-, también a la injusticia - "caceria"-, y a la estupidez: el terrorismo está de lo más agradecido a ese derroche por la guerra contra el terrorismo. "A la vista está que las guerras en Afganistán y en Irak le han regalado sus más poderosas vitaminas. Las guerras son actos de terrorismo de Estado, y el terrorismo de Estado y el terrorismo privado se alimentan mutuamente"16. Pero, lo que está en el fondo de todo es el agravio -e injusticia - en el despilfarro de recursos: nueve días de gastos militares alcanzarían para dar comida, escuela y remedios a todos los niños que no tienen.

Volvamos a la parábola. Lo que provoca es pasmo, un grito de "así no puede ser". Con anterioridad a toda conceptualización y a toda legislación surge una

14. En escritos como éste, siempre se suelen citar ejemplos escalofriantes de nuestro mundo, lo que gasta Europa en perfumes o en atención a mascotas... Quizás llevemos así 40 años y quizás el lector, aun sin atreverse a criticar que se meneionen esos desafueros, supongo que por pudor, piensa para sus adentros: "eso ya lo sabemos, dígannos algo nuevo". Se comprende, pero el tener que repetir "lo mismo", aunque con datos nuevos y diferentes, muestra que el agravio comparativo, inicuo y masivo, pertenece a la esencia histórica de occidente.

15. Eduardo Galeano, Conferencia pronunciada en el Foro de las culturas, Barcelona, Esparia, el 27 de mayo, 2004. Comenzó con estas palabras: "Nos reúne, en la mañana de hoy, la búsqueda de áreas de cooperación y de encuentro en este mundo enfermo de desvínculos".

16. Ibíd. 
protesta en contra de unos seres humanos, personas y pueblos, obscenamente opulentos, que coexisten con otros seres humanos miserables. La interpelación a una praxis para cambiar ese mundo es evidente, pero hay que valorar la suma importancia de captar el hecho en sí mismo y dejarse afectar por él.

El agravio comparativo es lo que impera en nuestro mundo. El lugar natural del rico, que diría Aristóteles, es el primer plano - muchas veces con boato insultante-, mientras que el lugar natural del pobre es la lejanía sin semblante, que no perturba nuestra tranquilidad, ni buen vivir. Es la inexistencia. Esa es la forma habitual de negar humanidad. Y eso es verdad también en regímenes democráticos, dentro de los propios países democráticos, y sobre todo en otros países que les están sometidos. Si se me permite la ironía a "la libertad, igualdad y fratemidad" hay que anteponer "la existencia" y "el nombre".

Podrá parecer poca cosa, pero, recordémoslo. Jesús pone nombre al miserable, $\mathrm{y}$ recordemos también que Jesús declara muy difícil, si no imposible, convertimos de la afrenta que causamos a los demás, por el mero hecho de ser tan infinitamente distantes unos de otros. Y tiene difícil solución. Ante el derroche de recursos para las guerras y para el buen vivir parece que no hay solución, "ni aunque un muerto resucite".

\subsubsection{La ultimldad de la misericordia}

El herido en el camino (Lc 10, 29-37). Es la conocida parábola del buen samaritano y, también, del sacerdote y del levita. En ella aparece una víctima tendida en el camino y las diversas reacciones. Hay salteadores que depredan, golpean y dejan medio muerta a la gente. Otros pasan de largo, y lo hacen activamente, "dando un rodeo", un sacerdote y un levita. Sólo el samaritano ayuda al herido.

Hoy puede preguntarse dónde está el analogatum princeps de la injusticia, en el comportamiento de estos actores. Ciertamente, hay injusticia en los salteadores activos, las grandes potencias, el G-8, las empresas multinacionales, las farmacéuticas, por ejemplo... Y el gran salteador es el imperio, Estados Unidos, que liderea la depredación, que lleva a cabo occidente. La globalización -aunque admite algunas lecturas positivas, sobre todo por los dinamismos que, de hecho, puede generar para el futuro si se trabaja en ello es fundamentalmente un maquillaje del imperio, que se impone de diversas formas: brutal, en contra de los debiles, y más sofisticada a parses allegados al imperio. Lo que en definitiva se impone es una manera de ser, presentada como salvación: la cultura del individualismo, del éxito y del buen vivir, como destino manifiesto. En su nombre se justificó la anexión de la mitad de México a Estados Unidos, en el siglo XLX, y ahora se justifica el buen vivir de los pocos, sin tener que preguntarse el precio que los muchos tienen que pagar por ello. 
Pero están también los que dan un rodeo. Es la injusticia por omisión, por no salvar de la muerte a mayorfas miserables, pudiendo hacerlo. Pues bien, ante la víctima en el camino, la re-acción primaria, acción por lo tanto, es la misericordia, la compasión, en lo que insiste Metz. Y digamos de paso que no es de extrañar su insistencia en que la cristología fundamental para nuestro tiempo sea la de los sinópticos, porque en ella es central la praxis y la compasión de Jesús, y la exigencia de su seguimiento.

Volvamos a la parábola. La misericordia aparece como lo primero y lo último, lo que surge del fondo del ser humano, de las entrañas - splachnizomai-, porque el sufrimiento de las víctimas ha llegado al fondo del ser humano. Para la misericordia no se necesita ninguna justificación -ni siquiera que haya mandamientos de la ley de Dios que la exijan-, ni nada nos puede eximir de esa obligación.

La misericordia es también el ejercicio de la "obediencia debida". Lo formulamos de forma chocante, sabiendo que la obediencia está desacreditada, en nornbre de la libertad, que puede ser egoísta, o en nombre de los dictados de la propia conciencia, cuando está bien formada. Pues bien, la misericordia es obediencia, porque hay una autoridad que puede exigirla: es "la autoridad de los que sufren". Y de ahí que tambien la libertad tenga que ser redefinida como aquella realidad del ser humano para el que nada es obstáculo para atender a la víctima, para hacer el bien.

Las víctimas nos confrontan con algo último. Reaccionar con misericordia es lo que define a Jesús: se deja afectar por el "Señor, ten misericordia de mr", y reacciona. Y desde la misericordia, define a Dios: el padre del hijo pródigo, y al ser humano cabal, el buen samaritano. Por lo que toca a la justicia, no basta con el movimiento de misericordia, obviamente, pero en ésta encuentra aquélla el dinamismo que la pone en marcha y le otorga dirección.

\subsubsection{Indignación: denuncia de la opresión y la hipocresía}

" Ay de ustedes, escribas, que imponen a los hombres cargas intolerables, pero ustedes no las tocan ni con uno de sus dedos!" (Lc 11, 46) ${ }^{17}$.

Jesús no tolera que al pobre se le desprecie o se lo ignore, y menos que se le afrente directamente, que se le pongan cargas intolerables. Es la condena explrcita y sin rodeos de la opresión que una clase, grupo, bloque, continente, ejerce contra otros y, como decfamos antes, como destino manifiesto, sin pudor. Es la condena de la opresión objetivada.

17. Los anatemas en Lc 11, 37-52 parecen más originales que los de Mt 23, 13-32. Los anatemas contra la fariseos recalcan más la hipocresfa, mientras que los dirigidos contra los escribas recalcan más la injusticia, el mal que hacen a los demás. Cfr. P. Benoit y M. E. Boismard, Sinopsis de los cuatro evangelios II, Bilbao, 1976, pp. 335ss. 
Y esa condena suele ir acompañada de circunstancias, que hacen de la opresión algo más inhumano todavía. En Lucas 22,24 s, que traspone las palabras de Jesús a la última cena para darles realce, Jesús resume siglos de historia: "los poderosos de este mundo gobieman como señores absolutos". Es el pecado fundamental, pero, además, "se hacen pasar por bienhechores" - muchas veces así se presentan el Consejo de Seguridad de Naciones Unidas, el Banco Mundial, el Fondo Monetario Internacional, la Organización Mundial del Comercio... -, lo cual une afrenta a la hipocresía. Tanto en Lucas como en Mateo, las denuncias contra la "injusticia" de los escribas va unida a la "hipocresía" de los fariseos, observación nada secundaria, si nos preguntamos si la injusticia del mundo occidental no va unida a la hipocresía de ser precisamente producto de "democracias", que proclaman que fueron a Irak - $o$ al menos ahora están - para implantarla. Y es muy importante la solemne proclama de Jesús: "no sea asf entre ustedes".

Lo que hemos dicho recoge cómo le afecta a Jesús el sufrimiento ajeno, injustamente infligido, la opresión que unos seres humanos ejercen sobre otros. Habrá que historizar para hoy lo dicho en este apartado, pero en la actualidad de nuestro mundo, no se avanzará hacia la justicia sin conciencia del agravio comparativo, la afrenta que este mundo - por el mero hecho de ser como es, incluidas las democracias - inflige a la mayorfa de los seres humanos. No se avanzará sin la ultimidad de la compasión ante las víctimas, como lo que es primero y último, anterior a la democracia y a la religión $-y$ hay que recordar lo que repite Metz: la religión de Jesús, que comenzó como religión sensible al sufrimiento, pronto se convirtió en religión sensible al pecado ${ }^{18}$. Y no se avanzará sin la indignación y denuncia de la opresión, tan unida ésta a la arrogancia y a la hipocresfa.

Para luchar contra la injusticia se necesitan muchas otras cosas, evidentemente, pero no debiera faltar lo que hace que la injusticia nos afecte con ultimidad. En mi opinión, esto no ocurre con facilidad, y de ah́ la importancia de que regresen los maestros de la sospecha para cuestionamos por qué la injusticia no posee ultimidad para reaccionar contra ella. Aquellos maestros de la sospecha de antaño, nos cuestionaban sobre Dios y la religión, y debemos estarles agradecidos. Creo que ahora nos deben cuestionar sobre occidente, la democracia, el mundo de abundancia, la prosperidad, el progreso. Más en concreto, sobre la incapacidad de reconocer la injusticia $-y$ de pedir perdón por ello. $Y$, positivamente, nos debieran animar a hacer lo que podemos llamar el primer acto de justicia: otorgar existencia a dos terceras partes de la humanidad, ponerles nombre y no dejarlas en el anonimato.

18. "La inquietante pregunta por la justicia para con el inocente que sufre, que está en la entraña de las tradiciones brblicas, se transformó con demasiada rapidez en la pregunta por la salvación de los pecados", "La compasión. Un prograna universal del cristianismo en la época del pluralismo cultural y religioso", Revisıa Latinoamericana de Teologí, 55 (2001), 27. 
Jesús no dejó teorfas ni praxis elaboradas para definir y combatir la injusticia. Pero nos dejó algo previo a todo ello: la ultimidad con que captaba lo inhumano. Hoy bien puede ser un necesario maestro de la sospecha. Y la ultimidad con que captaba lo humano. Hoy bien puede ser un maestro de la salvación.

\subsection{Jesús, defensor del débil y oprimido}

Jesús anuncia el reino de Dios a los pobres, lo inicia a través de una praxis y su religión es una religión política. Esto es bien conocido y ahora sólo queremos insistir en dos puntos del reino de Dios, relacionados con la justicia. Lo hacemos porque, por diversas razones, se están diluyendo en la actualidad y así se resta importancia a la justicia. Los dos puntos son la parcialidad, que cede hoy ante la globalización, y la praxis, que corre el peligro de aguarse ante una inadecuada espiritualización.

\subsubsection{La justicia del mesias y su parcialidad}

Jesús participaba de las esperanzas mesiánicas, y a ellas pertenecía la aparición del rey justo, el mesías, que después será identificado con su persona. Pues bien, en la tradición del Antiguo Testamento, el "rey justo esperado" no es cualquier rey, sino el rey parcial hacia los oprimidos. De ahr que "la justicia del rey... no consiste primordialmente en emitir un veredicto imparcial, sino en la protección que se preste a los desvalidos y a los pobres, a las viudas y a los huérfanos"19.

Esta parcialidad de la justicia choca - teóricamente - a nuestros ofdos occidentales democráticos, aunque en la realidad impera una obvia parcialidad, en la dirección opuesta: la justicia favorece más al poderoso que al débil, más al opresor que al oprimido -y eso tanto en el ámbito jurídico como en el ámbito más primordial de lo económico y social. Por eso es importante conocer cómo surgió en el mundo del Antiguo Testamento la idea y la necesidad de una institución que impartiese justicia. Pues bien, la función de lo que hoy llamamos juez era "exclusivamente para ayudar a quienes, por ser débiles, no pueden defenderse; los otros no lo necesitan". Y cuando la Biblia habla de Yahveh, como juez, piensa en su voluntad de "salvar de la injusticia a los oprimidos" 20 .

Lo que acabamos de decir es importante, en la actualidad, pues ha desaparecido la intuición de la parcialidad hacia el débil. Lo queremos ilustrar con lo que ocurre en un ámbito afín al de la justicia: los derechos humanos. En este campo no se pueden negar grandes avances leóricos, y también algunos avances prácticos. Pero ni en la teoŕa ni en la práctica se ha introducido en él la dimensión de parcialidad de la justicia mesiánica.

19. J. Jeremias, Teologia del Nuevo Testamento I, Santander, 1986, p. 122.

20. P. Miranda, Marx y la Biblia, 1972, p. 140 ss. 
Que no ocurre en la práctica es evidente, y asł el pueblo palestino, débil y oprimido, no es apoyado con especial interés - un interés "parcial" digamos- por el mundo occidental para que se le haga justicia. Lo que ocurre de hecho es que, en nombre de la imparcialidad, el mundo occidental no lo es, sino que más allá de las palabras, es parcial hacia el poderoso Israel' ${ }^{21}$. Eso es bien sabido.

Más complejo es plantear el problema a nivel teórico. La idea occidental de justicia proviene del mundo grecorromano y su símbolo es la mujer con los ojos vendados. De ahí que los documentos de derechos humanos comienzan con afirnaciones universales, imparciales. Dice la Declaración Universal: "Todos los seres humanos nacen libres e iguales en dignidad y derechos" (Art. 1).

La Declaración, en su conjunto, ha recibido críticas en los últimos años. Grupos feministas la critican por abstracta, pues no tiene seriamente en cuenta el género. Y lo mismo hacen grupos indígenas. La crítica fundamental es que tras la formulación universal, sólo se reflejan valores de occidente. Y Eduardo Galeano, con su ironía, sentencia: "No es por criticar, pero a la Declaración le falta mucho".

En mi opinión, sin embargo, y en un lenguaje brblico-teológico, el problema fundamental es que la Declaración se hace pasar por universal, en el sentido protologico, como si las cosas fuesen asi desde que el mundo es mundo, es decir, como lo que es connatural al ser humano por serlo. Pero, históricamente, es una afirmación escatológica, es decir: ojalá algún día, al final, las cosas sean asi, como coronación de un proceso histórico, que avanza hacia la escatología, en el doble sentido de lo que está por venir y de lo que es salvífico. A pensar esta tarea dedicó Ellacuría uno de sus últimos escritos.

Cuestion6, en primer lugar, el uso ideologizado de los derechos humanos: "el problema de los derechos humanos... propende a ser utilizado ideologicamente al servicio no del hombre, y de sus derechos, sino de los intereses de unos u otros grupos"22. La declaración de los derechos humanos no es, pues, tarea tan inocente como se suele presuponer. Para avanzar en una teoría, que esté en verdad al servicio del hombre y de la mujer, hay que replantearlos a la luz de un problema radical, que no consiste, primariamente, en la determinación de lo que

21. Otro ejemplo de actualidad. El general Romero Dallaire acaba de decir, viendo el comportamiento tan desigual de occidente ante Yugoslavia, por ejemplo, y ante Rwanda: "esto me llevó a la conclusión de que no todos los humanos son igualmente humanos, algunos son más humanos que otros, algunos cuentan más y la comunidad intemacional reacciona exactamente asf. Hubo más gente muerta y desplazada en Rwanda en 100 dras que en seis años de guerra en Yugoslavia. El mundo abandonaba a Rwanda mientras se llevaba miles de soldados a Yugoslavia y se destinaban miles de millones de dolares en ayuda".

22. I. Ellacuría, "Historización de los derechos humanos desde los pueblos oprimidos y las mayorfas populares", $E C A, 502$ (1990), 590. 
sea la naturaleza humana y su dignidad, sino que consiste en "la lucha de la vida en contra de la muerte, la busca de lo que da vida frente a lo que la quita o da muerte"23.

El dar vida, en contra de lo que da muerte, es la acción primaria con la cual se responde al derecho de los seres humanos. Y entonces, ese derecho exige una urgente historización - parcialización-, tanto por lo que toca a la realidad de la vida que hay que dar, como por lo que toca a los seres humanos que la tienen en peligro. Por lo que toca a la vida, empezando por la biológica, en nuestro mundo actual

puede parecer algo sobreentendido en los países más ricos, que tienen asegurado este derecho..., pero no es asi en la mayor parte de los parses, donde se hace sumamente problemático conservar la vida biológica, sea por la extrema pobreza, sea por la represión y la violencia. Para la mayor parte de la humanidad... no se dan las condiciones reales para poder seguir viviendo biologicamente - hambre y falta de lugar ${ }^{24}$.

No aparece aqui el lenguaje de parcialidad, pero sí la realidad objetiva que la exige. Dicho lapidariamente, lo fundamental es eliminar el hambre. Y lo mismo se desprende de estas otras palabras: "el estado del subdesarrollo es en sí mismo y en relación con estados de desarrollo una flagrante violación de la solidaridad humana, esto es de la naturaleza misma del fundamento de los derechos humanos y lleva consigo la permanente violación de esos derechos"23. El subdesarrollo es violación de los derechos humanos. Dicho gráficamente, si no se elimina el hambre, se destruye la solidaridad, y la proclamación de los derechos humanos no pasa de ser inane, cuando no una farsa.

Y si del contenido de los derechos se pasa a quienes los poseen, o no los poseen, vuelve a aparecer la parcialidad. "Es, de hecho, más importante ser ciudadano de un país poderoso y rico que ser hombre, aquéllo da más derechos reales y más posibilidades efectivas que ésto"26. Y la conclusión es sobrecogedora: "queda asi rota la solidaridad humana".

Todo esto significa que hay que cumplir con los derechos humanos no, en directo, para adecuar realidad y norma, ni siquiera naturaleza humana y su dignidad, sino para que la vida de los amenazados en la vida sea posible, y para que los seres humanos se lleven mutuamente y formen lo que debiera llamarse familia humana, no sólo especie.

23. Op. cit., p. 593.

24. Op. cit., p. 593.

25. I. Ellacuria, "Subdesarrollo y derechos humenos", Revista Latinoamericana de Teologla, 25 (1992), 4.

26. Op. cit., p. 5 s. 
Hay que superar, pues, la espúrea imparcialidad del derecho, que redunda en favor de los poderosos, y por eso hablamos de parcialidad. Con ello queremos decir que al pensar los derechos humanos y, en general, la justicia hacia los seres humanos, se tenga en mente, antes que nada, la vida de los pobres, y por cierto de los pueblos pobres. En ellos, y no en una abstracta universalización de la naturaleza humana, acaece lo humano concreto, lo que toda justicia y toda ley debe defender $r^{27}$. Y aclarémoslo con un comentario sobre la parcialidad, que está implícita en la opción por los pobres. De lo dicho se deduce no solo lo ilógico que es (como decía Juan Luis Segundo) añadir la palabra preferencial a la opción, sino también lo peligroso que es, pues debilita la parcialidad.

Volvamos a Jesús. "La buena noticia es únicamente para los pobres", dice J. Jeremias ${ }^{23}$, y suyo es también el énfasis "únicamente". Y de Dios se dice en la Escritura: "Padre de huérfanos y viudas es Dios" (Sal 68, 6). Es la raíz cristológica y teologal de la parcialidad. Monseñor Romero lo dijo de otra forma, hablando en Puebla con Leonardo Boff: "es preciso defender el mínimo que es el máximo de Dios: la vida".

En occidente hay que recordar que la democracia no pone en el centro de la sociedad al pobre, sino al ciudadano. Esto no niega que las democracias - aunque muchas veces a través de mecanismos injustos con los pobres del tercer mundohayan logrado mejorar algo la suerte de los pobres. Pero para la democracia no es central la parcialidad, y esa limitación teórica bien puede explicar por qué, para la totalidad del planeta, las democracias no generan mucha vida, sino que a veces generan muerte.

\subsubsection{La praxis histórica y la gratuidad}

El anuncio del reino es ya, en sí mismo, una praxis, una forma de configurar la conciencia colectiva, y así, de configurar también la realidad social. Y junto al anuncio, Jesús realizó otro tipo de actividades: curaciones, expulsión de demonios, acogida a débiles y pecadores, comidas con ellos... y practicó la denuncia profética de la injusticia. Pero lo que me interesa recalcar ahora es, ante todo, el hecho mismo de la dimensión práxica de la misión de Jesús y sus consecuencias para el creyente de hoy, pues, eclesial y aun teológicamente, se está diluyendo por varias razones.

Esto ocurre, en primer lugar, por los costos de la praxis de la justicia, como veremos más adelante. Ha habido una pléyade de mártires, de los cuales podemos estar orgullosos, pero cuya imitación, obviamente, asusta. Se buscan expli-

27. Cfr. Jon Sobrino, "Los derechos humanos y los pueblos oprimidos. Reflexiones histórico-teologicas", Revista Latinoamericana de Teologia, 43 (1998), 79-102.

2B. Op. cit., pp. 133, 142. 
caciones para ignorarlos, y se está haciendo obsoleto, aunque no se diga, relacionar el martirio con la praxis de Jesús.

Se insiste también en el peligro de que la praxis llegue a mutilar la totalidad cristiana y en dimensiones centrales, como lo es la oración-contemplación. Y es bueno apuntar al peligro, pues es evidente que el Jesús de la praxis también exige e invita a ponernos ante Dios como acto fundamental de la creatura. Pero también existe el riesgo de una praxis sin referencia a Dios.

Por último, se insiste hoy en la gratuidad de nuestro ser y hacer, recordatorio jesuánico, paulino y joanneo siempre necesario. La gratuidad es lo que nos hace salir de nosotros mismos y evita que la praxis pueda degenerar en provecho propio. La praxis, en efecto, puede llevar a la hybris, la arrogancia que deshumaniza. Para contrarrestar ese peligro, como bien dice González Faus, "hay que hacer la revolución como un perdonado".

Pero dicho esto, tampoco se puede negar que, en la actualidad, suele darse una insistencia unilateral en la oración, la espiritualidad y la gratuidad, lo cual puede generar una existencia cristiana light, que, sin llegar a convertirse, necesariamente, en cristianismo "barato" - en la línea de la gracia barata de Bonhoeffer -, nos distancia del cristianismo de Jesús, el cristianismo "caro" - en la linea de la gracia cara. La praxis de la justicia no debe deshumanizar, sabiendo que todo lo humano puede hacerlo, pero apelar a la contemplación y gratuidad tampoco puede anular realidades humanas y cristianas, que desde la perspectiva de la salvación sean quizás más primarias. El "denles de comer" o la pregunta de si vamos "a bajar de la cruz al pueblo crucificado", tienen una ultimidad que nada debe hacer desaparecer.

Para salvar ambas cosas, antes se solía insistir en el contemplativus in actione (contemplativo en la acción) de raigambre ignaciana, y en América Latiпа, se historizaba como contemplativus in liberatione ${ }^{29}, 0$ in actione iustitiae ${ }^{30}$. Para el cristiano es, pues, central la contemplación y la gratuidad. Pero sin praxis, sin hacer la voluntad de Dios, no se puede ser seriamente humano.

Esta praxis, además, debe ser dialéctica, pues tiene como horizonte no sólo el progreso, que debe ser humano, sino revertir una historia transida de injusticia. Por eso, Jesús añadra al anuncio, la denuncia de la injusticia. Debe estar dirigida, no sólo a la conversión de las personas, sino a la transformación de estructuras, por difícil que sea. Debe ser una praxis como lucha, pues tiene en frente de sí a los fdolos. Pero queremos insistir, para terminar, en la dialéctica más paradójica, y más específicamente cristiana, y la más difícil de aunar en la praxis: buscar la eficacia que necesita poder y hacerlo también desde la falta de poder.

29. L. Boff, "Contemplativus in liberatione". ECA, 374 (1982), 73.

30. I. Ellacurfa, “La contemplación en la acción por la justicia”, en Fe y justicia, Bilbao, 1999, p. 207. 
Por lo que toca al "poder", el poder de la gran economía y el militar no están en la línea jesuánica. Pero la praxis puede y debe hacer uso de otros tipos de poder, de los que usó Jesús, el poder de la palabra. Y hoy se debe hacer uso de poderes menos proclives al mal, por así decirlo: la organización popular, incluidos partidos políticos, la ciencia, la palabra... Y con ellos se puede ser eficaz ${ }^{31}$. Ignacio Ellacuráa insistió siempre en historizar los impulsos de la mística y convertirlos en praxis eficaz.

Queda otro paso también fundamental y es el de crear modelos económicos, políticos y culturales que hagan posible una civilización del trabajo como sustitutiva de una civilización del capital. $\mathrm{Y}$ es aquí donde los intelectuales de todo tipo, esto es, los teóricos críticos de la realidad, tienen un reto y una tarea impostergables. No basta con la crítica y la destrucción, sino que se precisa una construcción que sirva de alternativa real ${ }^{32}$.

Pero, por paradojico que parezca, esos poderes, en una praxis jesuónica, deben estar transidos de "la falta de poder". A la tradición jesuánica le compete que la salvación venga de lo pequeño, incluso de las víctimas; le compete recomer el carnino de la pobreza, no de la riqueza, y dirigirse hacia una civilización de la pobreza, que radique la actual civilización de la riqueza, que permita la vida de todos, que dé cabida al espiritu y que humanice a todos; le compete la disponibilidad a dar de la propia vida y aun la propia vida. Poner ambas cosas juntas, poder y sin-poder, no es fácil, pero hay que mantenerlo.

Volviendo a Jesús y la justicia, lo importante de este apartado es recordar que la pasión de Jesús por la justicia estaba permeada por la parcialidad hacia los pobres y por la praxis que construye el reino. Ambas cosas deben ser hoy recuperadas y puestas en primer plano del cristianismo.

Y una cosa más. La praxis debiera apuntar a la santidad, debe ser "santa", y de ahr que hace años escribiéramos sobre la necesidad de "una santidad política"33. Y a Ignacio Ellacuría le escuché estas palabras, en el año 1980, en un curso de eclesiología, "la última arma de los pobres es la santidad".

\subsection{Jesús, solidario y crucificado por causa de la justicia}

Este último apartado es fundamental al tratar de Jesús y la justicia, pues la causa de la condena a morir en cruz fue su lucha contra la injusticia, no cualquier otra cosa. Olvidar esto no es sólo mutilar gravemente la historia y la cristologfa, sino atentar contra la fe e ignorar que las millones de cruces del

31. L. de Sebastián, Razones para la esperanza en un futuro imperfecto, Barcelona, 2003. En las páginas finales, 211-236, hace un bello ejercicio del poder "no convencional", por decirlo de alguna manera, que puede ir cambiando, poco a poco, el mundo.

32. "El desafío de las mayorías pobres", ECA, 493- 494 (1989), 1078.

33. Así lo escribimos en Concilium, 183 (1983), 335-344. 
mundo actual se deben a la injusticia, no caen del cielo. Sin embargo, suele ignorarse. Y quizás, después de años de tenerlo en cuenta, tampoco la teología lo trata ahora con excesivo interés. Hace años no era asf, y citamos un texto de entonces, que viene como anillo al dedo:

Ninguna autoridad puede hacer que todo esté permitido, la justicia y la explotación no son tan indiscemibles como eso, y Cristo murió para que se sepa que no todo está permitido. Pero no cualquier Cristo. El que resulta definitivamente irrecuperable para el acomodo y el oportunismo es el Jesús histórico ${ }^{34}$.

El contexto teológico de esta cita era dar primacía metodológica en la cristología al "Jesús histórico". Y el contexto histórico era la lucha, en aquellos años, contra la justicia y la explotación. Lo importante es que la cruz expresa una correlación histórica esencial entre Jesús y la justicia. Por eso, volver a las causas que llevaron a Jesús a la cruz sigue siendo esencial. Pues bien, la muerte de Jesús se explica por la relación dialéctica de la divinidad (el Dios de vida y los dioses de muerte), de la mediación de la divinidad (el reino de Dios y una sociedad teocrática alrededor del templo, más la pax romana, en que estaba inserta) y de los mediadores (Jesús de Nazaret y los sumos sacerdotes, más Pilatos).

La cruz le sobreviene a Jesús por ser el mediador de un Dios, el Dios de la vida, y por anunciar una mediación, el reino de Dios para los pobres. El dinamismo del mal hace frontalmente contra Jesús, sin posibilidad de diálogo, complementariedad o negociación, lo cual es importante recordarlo hoy, no para exacerbar los problemas, ni ofrecer soluciones imposibles, pero sI por honradez con lo real. Al nivel de la subjetividad, bueno y necesario es desarrollar al máximo el diálogo, la tolerancia, la negociación, el realismo posibilista... Pero seŕa peligroso ignorar o quitar importancia a estructuras injustas y opresoras al nivel de la realidad objetiva Eso lo prohibe la cruz de Jesús. Recordemos dos textos, uno de Molmann y otro de Ellacurfa:

Jesús fue crucificado por los romanos no sólo por razones tácticas y- de política diaria de tranquilidad y orden en Jerusalén, sino, en definitiva, en nombre de los dioses estatales de Roma que aseguraban la pax romana ${ }^{35}$.

Jesús y sus enemigos representan dos totalidades distintas, que pretenden dirigir contrapuestamente la vida humana; se trata de dos totalidades prácticas, que llevan la contradicción al campo de la existencia cotidiana ${ }^{36}$.

Ni la vida ni la muerte de Jesús se pueden comprender sin su lucha contra la injusticia y la reacción de ésta. Dicho en positivo, no se pueden comprender sin su amor y defensa de los oprimidos, sin su lucha para revertir esa opresión en vida.

34. Porfirio Miranda, El ser y el Mesfas, Salamanca, 1973, p. 9.

35. J. Moltmman, El Dios crucificado, Salamanca, 1974, p. 194.

36. I. Ellacuría, "Por qué muere Jesús y por qué le matan", Diakonía, 8 (1978), 66. 
Para Jesús, vida y muerte de los pobres, opresión y liberación, injusticia y justicia fueron realidades que le configuraron con ultimidad. Tras todo ello, resonabą en su experiencia personal, la mejor tradición teologal de Israel. "Padre de huérfanos y viudas es Dios" (Sal 68,6), de modo que la verdadera confessio Dei de Israel es la exclamación: "en ti el huérfano encuentra compasión"37.

Nada concreto hemos dicho sobre Jesús y la justicia. S6lo hemos reflexionado alrededor del tema. Para algunos, mejor será abordar los problemas de nuestro mundo sin la radicalidad que exige Jesús y que se simbolizan en el término "justicia". Quizás se consigue más para los pobres, por los caminos del "progreso" posible, el diálogo sin estruendos, la tolerancia sin antagonismos... Lo que queda claro, sin embargo, es que, sea cual fuere la decisión en favor de la justicia o de un progreso que llegará a todos algún día, occidente, dicho de la manera más sencilla, debe escuchar estas dos frases de Jesús y decidir qué hacer con ellas.

La primera es una pregunta. "¿Dieron o no dieron de comer al hambriento? Y recuerden que allí estaba yo" (Mt 25, 31-46). Y si ponemos la pregunta en boca de los pueblos pobres y oprimidos, usando aquella antigua tradición cristiana de que son vicarios de Cristo, puede sonar así: "¿qué haces occidente, opulento, que te precias de democracia - como antes de cristianismo-, con nosotros, gran mayoría de la humanidad, que no llegamos a ser ciudadanos del planeta, aunque sabemos que Dios está con nosotros?".

La segunda es una afirmación lapidaria para que nadie se llame a engaño: "nadie puede servir a dos señores; porque aborrecerá a uno y amaŕ al otro; o bien se entregará a uno y despreciará al otro. No pueden servir a Dios y al dinero" (Mt 6, 24; Lc 16, 13).

37. Citado en P. Miranda, Marx y la Biblia, p. 74 